\title{
ANL Advanced Photon Source Crotch Absorber Design $\dagger$
}

\author{
M. Choi*, J.D. Gonczy, J.W. Howelh and R.C. Niemann \\ Argonne National Laboratory 9700 Cass Ave Argonne, IL 60439 \\ *Seoul National University San 56-1 Shinrim-Dong Kwanak-ku Seoul 151 Korea
}

\section{Abstract}

The ANL 7-GeV Advanced Photon Source storage ring crotch absorber will be subjected to a very high photon loading power density, approximately $750 \mathrm{~W} / \mathrm{mm}^{\wedge} 2$ at normal incidence. To accommodate this high heat load, two designs were studied: one is a V-type compound angle absorber and the other is a horizontally rotated plate absorber. For both models, thermal and structural analyses bave been carried out using 3-D finite element analysis. The analysis indicates that the V-type compound angle absorber controlled the peak temperatures effectively within the given geometric constraints. Test samples made of GlidCop AL 15 (alumina dispersion strengthened copper) were evaluated with an electron beam welder. The predicted and measured temperatures were in reasonable agreement. The overall absorber design includes a perforated screen in the positron beam area of the storage ring vacuum chamber to reduce $\mathrm{RF}$ impedance and to provide pumping access for the high local gas load.

\section{INTRODUCTION}

The machine parameters of the Advanced Photon Source (APS) storage ring are $\mathrm{E}=7 \mathrm{GeV}, I=300 \mathrm{~mA}$ (nominal current is $100 \mathrm{~mA}$ ) and $\mathrm{B}=0.6 \mathrm{~T}$ for the bending magnets. Each of the 80 bending magnets in the storage ring produces an intense beam of synchrotron radiation. The horizontal fan of radiation from each magnet is about $78.5 \mathrm{mrad}$. A maximum of $6 \mathrm{mrad}$ of this radiation is used by the experimental beam lines.

Most of the remaining non-experimental synchrotron radiation is absorbed by photon absorbers in order to minimize the number of photons striking the wall of the vacuum chamber. The crotch absorber is located just downstream of the bending magnet at the point of divergence of the pasitron beamline and synchrotron radiation beamline (Fig. 1).

The crotch absorber is subjected to the highest normal incident power density because of its proximity to the bending

†Work Supported by U.S. Department of Energy, Office of Basic Sciences under Contract No. W-31-1-9-ENG-38. magnet. The power density of the synchrotron radiation that strikes the absorber varies in both the horizontal and vertical planes. The density varies gradually in the horizontal plane but has a near Gaussian profile in the vertical plane with a $u=$ $0.09 \mathrm{~mm}$ on the portion of the absorber closest to the positron beam. The maximum normal incidence power density at this point is $750 \mathrm{~W} / \mathrm{mm}^{\wedge} 2$. The vertically integrated power density or linear power density at this point is $149 \mathrm{~W} / \mathrm{mm}$. It is this extremely high heat flux that drives the design of the crotch absorber.

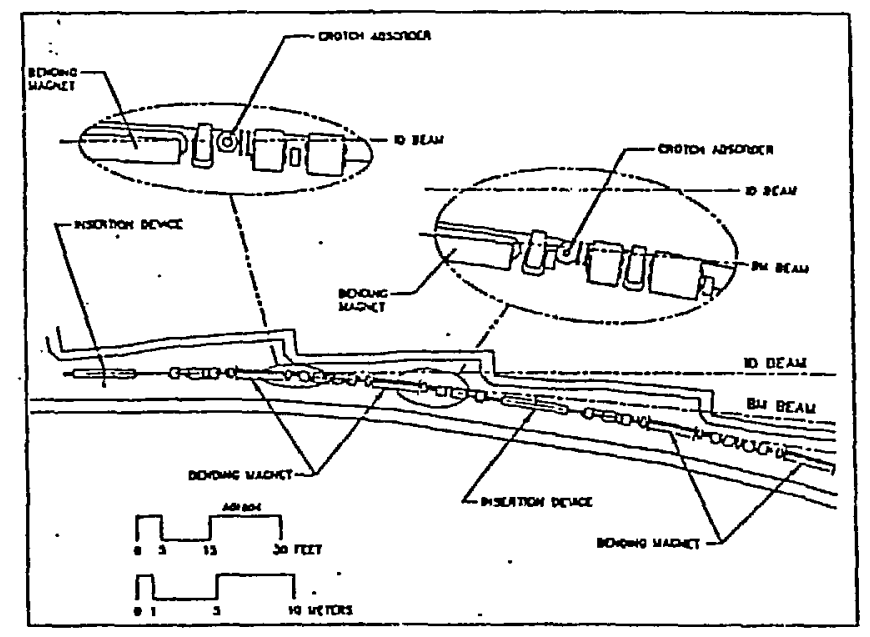

Fig. 1 Location of Crotch Absorbers

\section{DESIGN CRTTERIA}

The design of the crotch absorber must provide for the removal of this localized heat load while maintaining the structural integrity of the absorber during steady state and cyclic operation of the storage ring. The configuration for cooling the absorber must allow the use of water as the coolant. To prevent the possibility of film boiling, the allowable maximum temperature of the wetted surface is set to be below the saturation temperature of the pressurized water. Also, the absorber thermal and photon induced desorption levels must be within limits so as not to degrade the storage ring's overall vacuum level. Specific structural and thermal design criteria are listed in Table 1.

\section{MASTER}

DISTRIEUTION OF THIS DOCUMENT IS UNLIMITED 
Table 1 - Absorber Design Criteria

$$
\begin{gathered}
\text { Thermal Condition } \\
\mathrm{T}_{\text {water }}<\mathrm{T}_{\text {boil }}=150^{\circ} \mathrm{C} \text { at } 5 \text { ATM } \\
\mathrm{T}_{\text {sure }}<0.5 \times \mathrm{T}_{\text {melt }}=541^{\circ} \mathrm{C} \text { for Copper }
\end{gathered}
$$

Structural Condition

$$
\begin{gathered}
\text { Thermal Stress }<2 \times \mathrm{S}_{\mathrm{Y}}(0.2 \% \text { Yield Strength) } \\
\text { and } \\
<\mathrm{S}_{\mathrm{F}} \text { (Fatigue Strength) for } 10^{5} \text { Cycles } \\
\text { and } \\
\text { Thermal Stress }<\mathrm{S}_{2}(\mathrm{Hot})+\mathrm{S}_{2}(\text { Cold })
\end{gathered}
$$

\section{DESIGN DESCRIPTION}

The basic concept in the design of the APS crotch absorber is to increase the photon beam shining area as much as possible within the allowed space in order to decrease the linear power density. Several designs have been considered, including the horizontally rotated absorber and the V-type compound angle absorber. The difficulty in designing the inclined crotch that will handle the fan of bending magnet radiation is that comer photon heating is inevitable. Comer heating produces a local hot spot. For example, the horizontally rotated absorber would have a peak surface temperature of $500^{\circ} \mathrm{C}$ on the corner region near the synchrotron radiation beamline. The effective spread of photons in a compound grazing angle of the V-type compound angle absorber is found to reduce the local hot spot and thus reduce the peak surface temperature significantly.

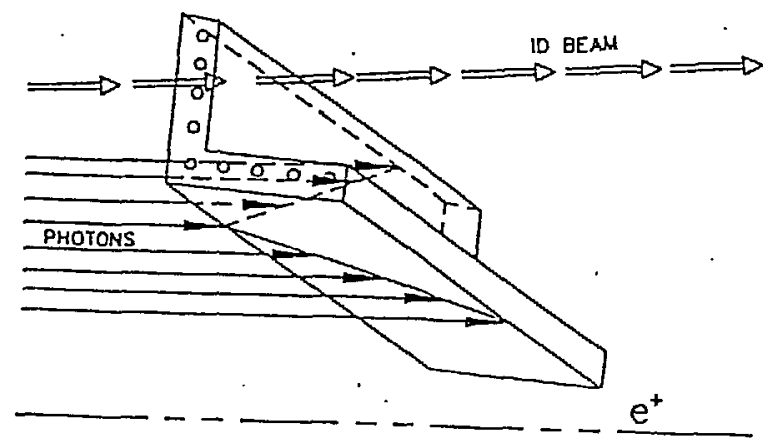

Fig. 2 Compound-V Absorber Concept

\section{ANALYSIS}

Thermal and Structural analysis has been conducted for both the horizontally rotated absorber and V-type compound angle absorber using the finite element program ANSYS. The results for the V-type compound angle absorber are summarized in Table 2 for a variety of plate thicknesses and convection heat transfer coefficients.

As Table 2 shows, the peak thermal stress on the surface is very high due to localized heating. The stress varies little for different cooling rates and that necessitates the use of a copper alloy with a yield strength much larger than OFHC copper. The most likely material is GlidCop [1] AL-15 Extruded (alumina dispersion strengthened copper). Room and elevated temperature tensile tests have been conducted on Glidcop samples annealed at $850^{\circ} \mathrm{C}$ for $1 / 2$ hour. The peak thermal stress exceeds the yield strength of annealed GlidCop, therefore plastic defornation will occur. Since copper is a ductile material, the plastic flow does not necessarily result in failure. The use of GlidCop will satisfy the structural conditions specified in Table 1.

Table 2 - Finite Element Results for V-type Absorber

\begin{tabular}{ccccc}
\hline $\begin{array}{c}\text { Plate thickness } \\
(\mathrm{mm})\end{array}$ & $\begin{array}{c}\mathrm{h} \\
\left(\mathrm{W} / \mathrm{mm}^{\wedge} 2-^{\circ} \mathrm{C}\right)\end{array}$ & $\begin{array}{c}\mathrm{T}_{\text {surt }} \\
\left({ }^{\circ} \mathrm{C}\right)\end{array}$ & $\begin{array}{c}\mathrm{T}_{\text {water }} \\
\left({ }^{\circ} \mathrm{C}\right)\end{array}$ & $\begin{array}{c}\text { Thermal stress } \\
\left(1000 \mathrm{lb} / \mathrm{in}{ }^{\wedge} 2\right)\end{array}$ \\
15 & .015 & 348 & 116 & 54.0 \\
15 & 0.035 & 318 & 82 & 57.5 \\
7 & 0.035 & 302 & 107 & 56.0 \\
\hline
\end{tabular}

\section{ELECTRON BEAM TESTS}

To verify analytical results, electron beam tests have been performed on models of the horizontally rotated absorber and the V-type compound angle absorber. The tests are performed by rastering the electron beam to simulate the linear heat flux of the horizontal fan of bending magnet radiation. The measured temperatures are in reasonable agreement with the values predicted from the finite element mosel (Fig. 3). Note that the measured values were calibrated to the back scattering efficiency of electrons on the inclined surface of copper using the following equation [2]:

$$
\eta^{\prime}(a b s o r p t i o n \text { coeffcient })=1-\frac{1}{(1+\sin \theta)^{p}}
$$

$$
\text { where } p=\frac{9}{\sqrt{2}}
$$


No surface damage was observed on any electron beam test sample when a rastering frequency of $10 \mathrm{Khz}$ was used. However, at lower fiequencies thermal microcracks were observed during mictoscopic examination of the sample surface. At the lower frequency rastering surface damage was caused by periodic non-uniform heating, which produced rapid fluctuations in surface stress.

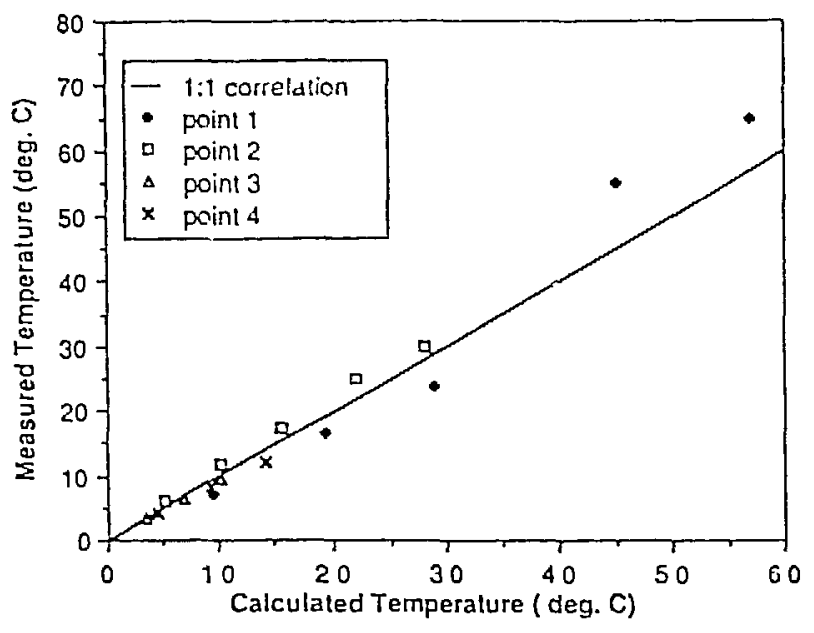

Fig. 3 Electron Beam Test Results

\section{CONSTRUCTION}

The construction of the absorber consists of two halves, one with milled water channels, joined by vacuum brazing. The braze joint consists of two joints with a vented air gap between them [3]. This design prevents a water leak to the ultra-high vacuum in the event of a single braze failure. To assure reliable braze joints the surfaces to be joined will be covered with oxygen free high conductivity (OFHC) copper. This will be accomplished by using OFHC clad GlidCop or by electroplating OFHC copper onto GlidCop.

The front portion of the absorber will also have parallel copper plates attached to it in order to intercept back scattered photons, especially fluorescence photons, that would otherwise heat the surrounding vacuum chamber.

The crotch absorber will be installed in the vacuum chamber through a pair of 12-inch diameter Conflat flanges located on the top and bottom of the chamber. Cooling water feed-throughs will be connected through the top flange and lumped pumps will be connected to the bottom flange.

\section{PUMPING}

The desorbed gas load will be large at the crotch absorber. Lumped pumping consists of one $220 \mathrm{-1} / \mathrm{s}$ ion and one

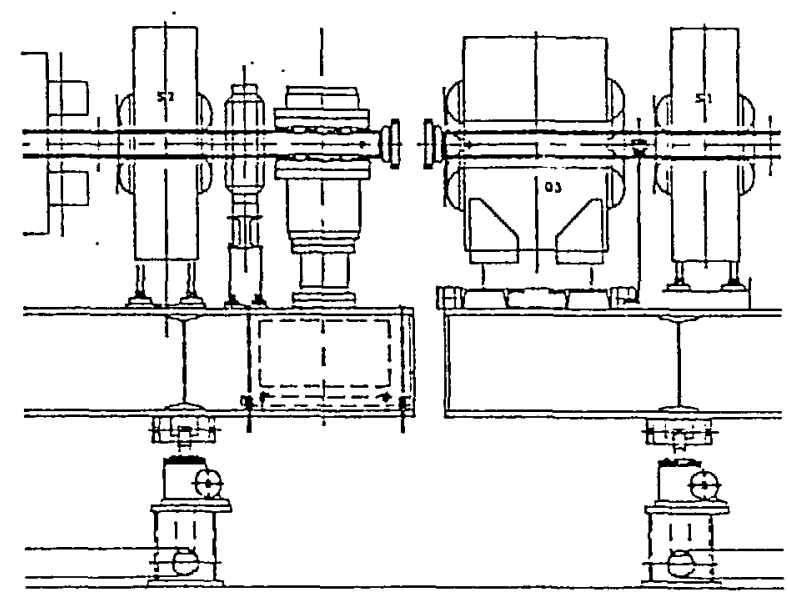

Fig. 4 Crotch Absorber Pumping

1000-1/s Non-evaporable Getter (NeG) pump. They are located directly under ihe absorber (Fig. 4). The NeG pumps do not pump $\mathrm{CH}_{4}$ and noble gases and must be augmented with ion pumps.

The penetrations in the vacuum chamber for the crotch absorber and its associated pumping result in discontinuities in the vacuum chamber cross sections. The RF impedance of these discontinuities is minimized by the installation of screens that match the contour of the vacuum chamber. These screens contain perforations to allow gases desorbed at the crotch absorber to be conducted to the lumped pumping.

\section{ACKNOWLEDGEMENTS}

The authors wish to thank the APS vacuum and mechanical group staff for their assistance. Special thanks go to Robert Wehrle for bis valuable consulation, and to Rich Ferry for his skill and effort in support of the electron beam tests.

\section{REFERENCES}

[1] GlidCop is a product of SCM Metal Product, Inc.

[2] J. Goldstein et al, Scanners Microscopy and X-ray Microanalysis p. 79

[3] T. Swa:n, Thermal Absorber Design for ALS Beamlines, LBL Eng. Note, Jan, 1989 